\title{
Adaptation of Camelus dromedarius pars nervosa of the hypophysis to winter and summer living conditions
}

\author{
Fatma Zohra Djazouli Alim¹, Manuel Jose Rodríguez², Carmen Andrade², \\ Nemcha Lebaili ${ }^{3}$, Nicole Mahy ${ }^{2}$
}

${ }^{1}$ University SAAD Dahleb, Department of Agro-Veterinary Biological Sciences, B.P. 270 route de Soumaa Blida, Algeria

${ }^{2}$ Unitat de Bioquímica i Biologia Molecular, Facultat de Medicina, Institut d'Investigacions Biomèdiques (IDIBAPS), Universitat de Barcelona and Centro de Investigación Biomédica en Red sobre Enfermedades Neurodegenerativas (CIBERNED), Barcelona, Spain

${ }^{3}$ Ecole Normale Supérieure, Laboratoire de Physiologie Animale; E.N.S de Kouba Bachir El Ibrahimi, B.P 92, 16050 Algeria

\begin{abstract}
The aim of this work is to study the characteristics of the dromedary nervous lobe and determine how the seasons condition its organization. To this end, electron microscopy was performed and examined quantitatively on animals from winter and summer periods. The results show a higher number of cells in the nervous lobe in summer than in winter. The most abundant glial elements in winter are light pituicytes engulfing neurosecretory nerve fibers making neuroglial contact, and dark pituicytes containing numerous heterogeneous light bodies. In summer, the most distinctive glial cells may be pituicytes in a phagocytic state making contact with characteristic large light bodies that could represent a degenerative process of large neuropeptide storage. Granular pituicytes were also observed in contact with glial and neuronal components. However, lipid droplets, described in pituicytes of other mammals, were not observed in our samples. Quantitative analysis of neurovascular contacts revealed that the number of nerve terminals contacting the basal lamina did not differ between summer and winter, but the mean number of glial processes increased in winter. Our data provides evidence that the storage of neuropeptides is very marked in summer and that, associated with an autophagic and phagocytic phenomenon, this suggests an adaptation to anticipate any situation that would cause dehydration of the dromedary. Thus, in its tough environment, the animal remains permanently prepared to avoid any large water loss. (Folia Histochemica et Cytobiologica 2012, Vol. 50, No. 2, 203-212)
\end{abstract}

Key words: dromedary, neural lobe, ultrastructure, winter, summer

\section{Introduction}

Mammals maintain their water balance under conditions of dehydration through secretion of large amounts of vasopressin [1], which is stored within the nervous lobe (NL) of the hypophysis. Many ultrastructural studies have described its organization in rodents

Correspondence address: N. Mahy,

Unitat de Bioquímica i Biologia Molecular,

Facultat de Medicina, Institut d'Investigacions Biomèdiques

(IDIBAPS), Universitat de Barcelona,

C. Casanova, 143-08036, Barcelona, Spain;

e-mail:nmahy@ub.edu,zahralim@yahoo.com
[2-7]. The main elements of NL are the neurosecretory axons and terminals of the hypothalamic magnoneurons closely associated with a variety of astrocyte-like cells, like the pituicytes of major functional importance. The NL neurosecretory neural component has been subdivided into: (a) axons coming from the hypothalamus, (b) nerve fiber endings, and (c) nerve fiber swellings, which differ in the location, size and volumetric density of neurosecretory granules (NSG), and the microvesicles, only found in nerve fiber endings [ 8,9 cited by 10]. These structures end on pituicytes or the basal lamina (BL) of fenestrated capillary walls. The neuropeptides synthesized in the cell bodies of magnoneurons are transported to the 
NL via the hypothalamo-hypophyseal tract and stored in the NSG [11]. They are secreted into the blood circulation under appropriate stimuli, such as acute or chronic dehydration, parturition, or saline solution beverage [12]. Whereas standard experimental studies have assumed a rodent NL structural remodeling caused by different laboratory conditions [12-15], our approach allows for an explanatory relationship between true living conditions and NL adaptation.

In this paper, the NL plasticity of the dromedary (Camelus dromedarius), a mammal of the hot desert (Sahara) that walks long distances and can survive a lack of water for months, is analyzed. This approach aims first to characterize the dromedary NL organization, and then to identify its seasonal adaptation to arid conditions.

\section{Material and methods}

The hypophysis of healthy Algerian adult male dromedaries, Camelus dromedarius, were collected after slaughter for human consumption in the Golea slaughterhouse, situated in the central Algerian Sahara $\left(30.57^{\circ} \mathrm{N}, 20.87^{\circ} \mathrm{E}\right)$, in winter $(\mathrm{WG}, \mathrm{n}=3$ ) and summer $(\mathrm{SG}, \mathrm{n}=3)$. After hypophysis extraction, the neural lobes were rapidly dissected and immersion fixed. For light microscopy, specimens were fixed in $10 \%$ phosphate-buffered formalin for at least one week and processed for paraffin embedding. Sections $(10 \mu \mathrm{m})$ were prepared and stained with hematoxylin and eosin and Crossman's trichrome [16] combined with Hansen nuclear stain.

For electron microscopy, specimens of about 1 to $2 \mathrm{~mm}^{3}$ were cut and then fixed in $2.5 \%$ glutaraldehyde in $0.1 \mathrm{M}$ phosphate buffer $(\mathrm{pH} 7.4)$ at $4^{\circ} \mathrm{C}$, and postfixed at $4^{\circ} \mathrm{C}$ in $2 \%$ osmium tetroxide in the same fixative for $1 \mathrm{~h}$. Samples were then thoroughly washed with distilled water and dehydrated in graded ethanol and propylene oxide, and finally embedded in Spurr's resin. Semi-thin and ultrathin sections were obtained using a Reichert-Jung Ultracut E ultramicrotome. The first sections were stained with toluidine blue. The ultrathin sections were placed on copper grids and double-stained with uranyl acetate and lead citrate [17], then examined with a JEOL 1010 TEM.

Photomicrographs were used for quantitative studies using MacBiophotonics Image $\mathbf{J}$ software. For statistical analysis, each animal was considered as one sample. Semithin sections from each animal were used to calculate the number of pituicytes and means \pm SEM were calculated from 12 square areas of $100 \mu \mathrm{m}^{2}$ from three semi-thin sections of each animal (A1, A2, A3). The mean number of pituicyte processes and nerve fiber terminals per $100 \mu \mathrm{m}$ of BL were determined on ultrathin sections (5-10 photomicrographs per animal) as described by Tweedle and Hatton [12]. Morphometrical measurements were made using Image Tool
- IT300 software. For each parameter, Kurtosis and Skewness moments were calculated to test the normal distribution of the data. Then one-way ANOVA, followed by the leastsignificance difference (LSD) post hoc test, was used to compare differences between the winter and summer groups. Values of $p<0.05$ were considered statistically significant. All analyses were performed with the PAST 1.37 statistics package (PAleontological STatistics, University of Oslo).

\section{Results}

\section{Camelus dromedarius neural lobe organization}

Under light microscopy, the NL of the Camelus dromedarius hypophysis appeared to be surrounded by intermediate and anterior lobes with a pseudo-lobulated pattern (Figure 1A). These pseudo-lobules, delimited by septa, had abundant collagen and were richly vascularized (Figure 1C), the hilar zone being central (Figure 1B). Supporting tissue (Figure 2A), forming a thick slice (Figure 2B) with fibroblast and glial cells (Figure 2C), isolated the NL parenchyma from the intermediate lobe. The main NL components were glial cells (mostly pituicytes), neurosecretory nerve fibers and neurovascular zones. The pituicytes appeared scattered throughout the parenchyma and intermingled with unmyelinated neurosecretory nerve fibers (Figure 2D). In the NL, the septa included separating and mechanical supporting elements that contained BL, pericytes, collagen and blood vessels (Figure 2E). In the neurovascular zone, a ramified $\mathrm{BL}$ in contact with neurosecretory nerve fibers containing NSG and fenestrated capillaries was observed (Figure 2F).

\section{Summer and winter differences in Camelus dromedarius neural lobe}

Two specific NL summer group (SG) characteristics were observed in semi-thin sections: (a) the presence of large light structures (Figure 3B), easily identified in the ultrathin sections (Figure 3B1), which were absent in the winter group tissue (WG) (Figures 3A and $\mathrm{A} 1$ ); and (b) a greater number of larger cells in the SG $(p=0.0089)$ (Figure 3C).

The most abundant glial cells of the WG were of the light (Figures 4A, B, B1) and dark types (Figures $4 \mathrm{C}, \mathrm{D}, \mathrm{E})$. The first type partially surrounded or completely enclosed numerous neurosecretory nerve fibers in its cytoplasm (Figures 4B, B1), and the second enclosed light bodies of different sizes (Figure 4D). Frequently, these cells contained neurosecretory axonal profiles with granulations (Figure 4E1) and light vacuoles with granulations (Figure 4E2). 

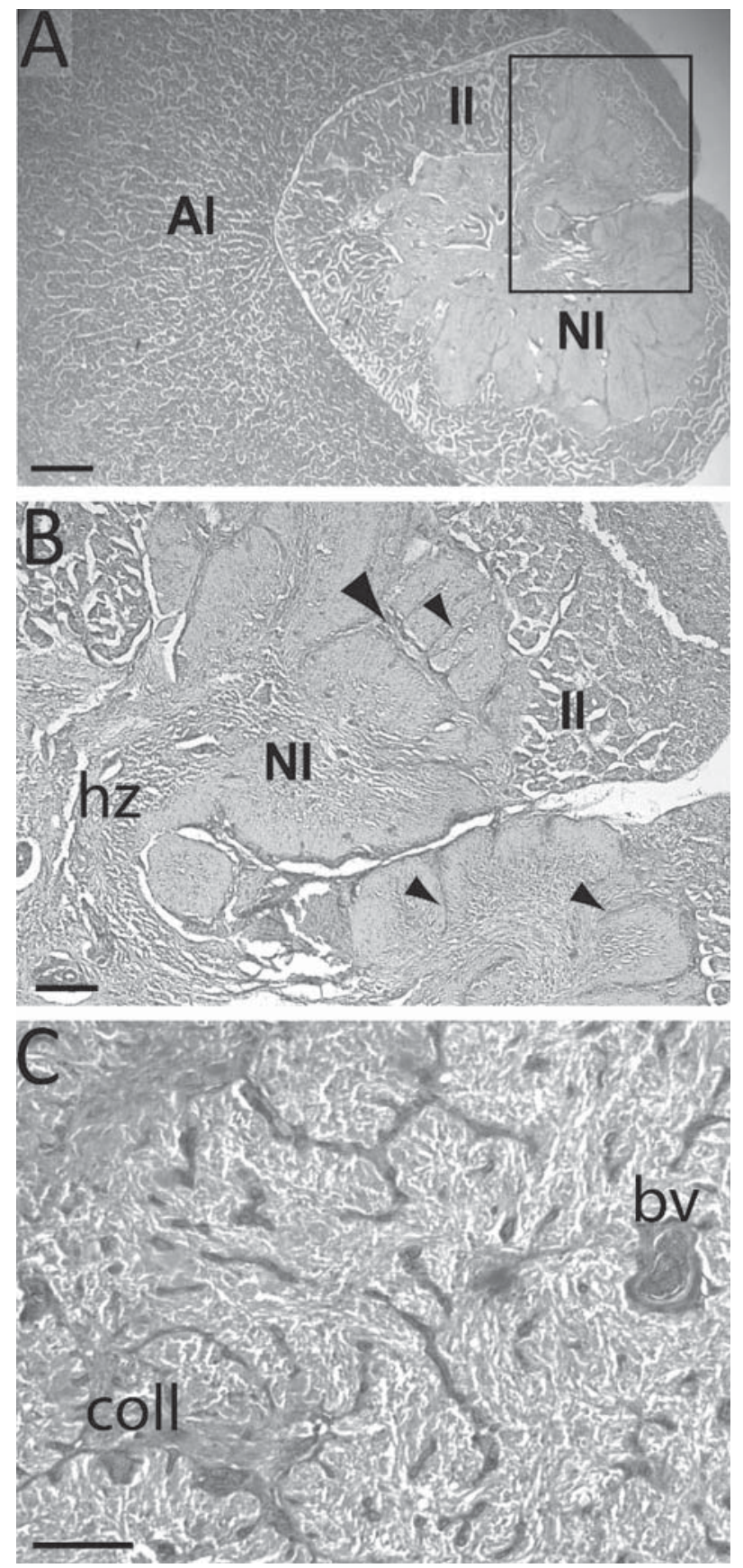

Figure 1. (A) Dromedary pituitary gland, (N1) nervous lobe, (Il) intermediate lobe, (Al) anterior lobe. (B) Magnification of the rectangle in (A) showing the pseudo-lobular organization of $\mathrm{Nl}$ parenchyma. Palisade (small arrow head) strengthened the connective septum (large arrow head). The central fibrous area is the hilar zone (hz). H\&E. (C) The connective parenchyma with abundant collagen (coll) in palisade and septa with blood vessel (bv). Trichrome-Hansen. Scale bar A = $1 \mathrm{~mm}(\times 12.5) ; \mathbf{B}=100 \mu \mathrm{m}$ $(\times 50) ; \mathbf{C}=50 \mu \mathrm{m}(\times 100)$

In SG, the frequent cells observed were of phagocytic type (Figures 5A, B, C); their plasma membrane was well defined and slightly indented by neighbor- ing neurosecretory nerve fibers. The cytoplasm contained numerous mitochondria (Figure 5A1) and their nuclei were irregular (Figure 5A), indented (Figure 5B) or elongated (Figure 5C) due to the presence of large, heterogeneous light body inclusions that contained irregular degenerating neurosecretory profiles (Figures 5B1, C1) with small granules (Figures 5B1, $\mathrm{C} 2$ ). The late stage of the phagocytic process was represented by a phagosome completely enclosed within the cytoplasm (Figure 6A) and surrounded by a thick, dense membrane, numerous distended Golgi cisterns and rough endoplasmic reticulum, with a dense body in the vicinity. Processes containing small dark granulations made contact with this cell type (Figure 6A1). The granulations apparently come from neurosecretory nerve fibers (Figure 6B). The processes are from a granular type of pituicytes; in these last, cisterns of rough endoplasmic reticulum were present (Figures $6 \mathrm{~B} 1, \mathrm{~B} 2$ ) and distinguished from neurosecretory nerve terminals (Figure 6B2).

The neurosecretory profiles of SG and WG were structurally distinguishable, with light and dark neurosecretory nerve fiber profiles, and with more dense granules in the SG (Figures 7A, A1). Only the SG presented large, light empty bodies. The organization of nerve fiber endings in the vascular zones (Figures 7B, B1) appeared structurally different in shape, with in both groups few pituicyte processes between them (Figures 7B1, C) but with abundant microvesicles in nerve fiber endings of the SG (Figure 7C1). When measured, the mean number of nerve fiber terminals contacting BL per unit length was not significantly different between groups, but the mean number of glial processes was significantly increased in the WG $(\mathrm{p}<0.05)($ Table 1$)$.

\section{Discussion}

This paper describes for the first time the dromedary NL organization and the seasonal influence on its different features. In summer arid conditions, the characteristic large light body structures observed in the dromedary neurosecretory nerve fiber swellings may reflect the NSG depletion of these structures, similar to the rat after a rehydration period $[11,20]$, and with an increased lysozymal activity or a continuous movement of the NSG towards the nerve fiber endings. Rehydration after osmotic stimulation [7, 18-20] or recovery from lactation [21] presents an autophagic activity in terminal and pre-terminal axonal parts to probably regulate a previously increased synthesis and transport [7]. As also observed after section of the pituitary stalk [22-25], and in human NL [26], in the 

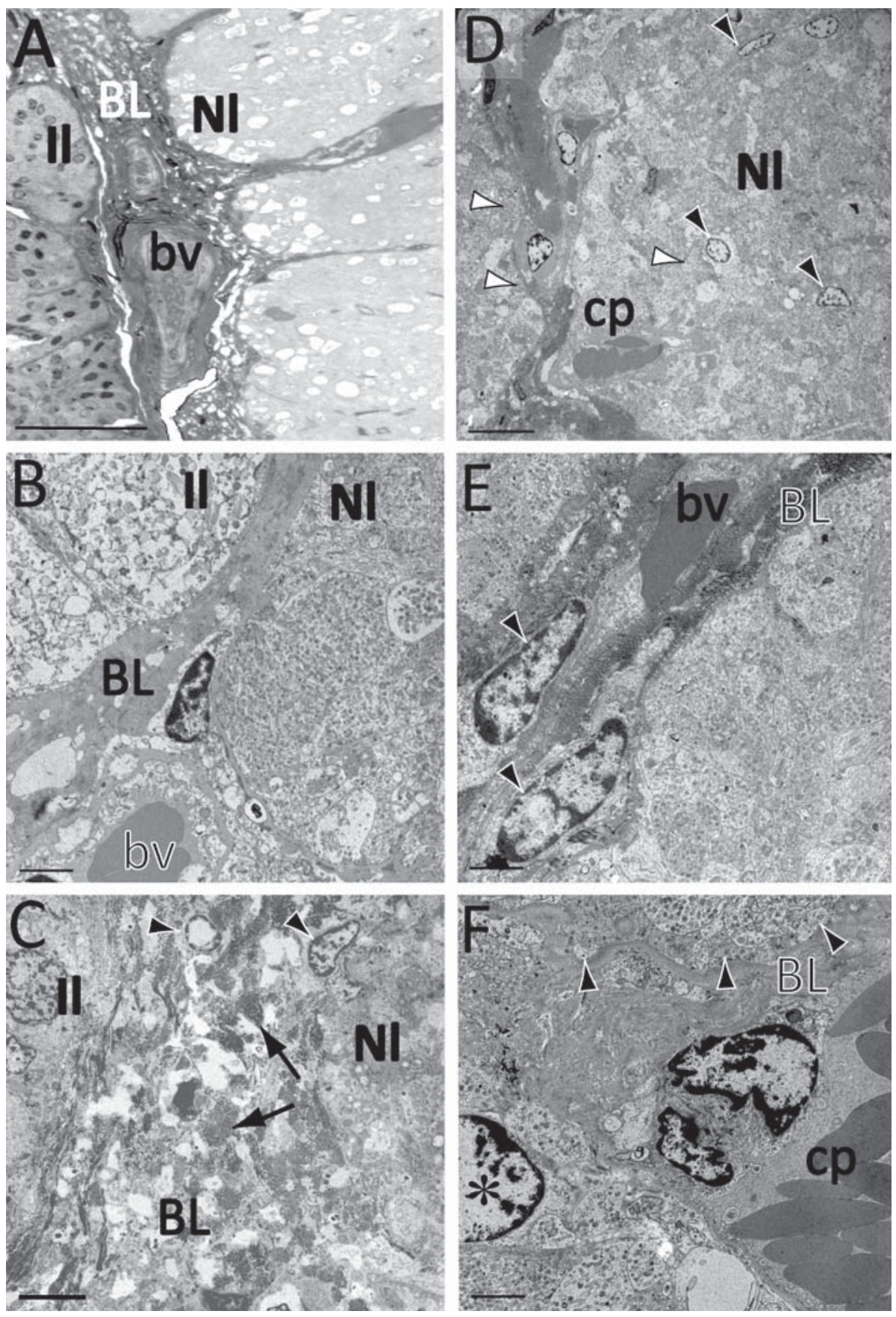

Figure 2. Fine structure of dromedary nervous lobe. (A-C) Neuro-intermediate contact zone. (A) semi-thin section of the border between Il et Nl. (B) Basal lamina electronogram (BL) between II and Nl, blood vessel (bv). (C) A basal lamina (BL) with collagen (arrows) and fibroblasts (arrowheads). (D-F) Nl parenchyma. (D) Numerous pituicytes (dark arrowheads), axonal endings (white arrowheads) and capillary (cp) in Nl. (E) Palisade zone with connective tissue, blood vessels (bv) with pericytes (arrowheads) in basal lamina (BL). (F) Neurovascular contact zone apposition with axonal terminals (arrowheads) to the basal lamina (BL), capillary (cp) with erythrocytes, pituicyte (asterisk). Scale bar $\mathbf{A}=50 \mu \mathrm{m}$;

$\mathbf{B}, \mathbf{E}, \mathbf{F}=2 \mu \mathrm{m} ; \mathbf{C}=5 \mu \mathrm{m} ; \mathbf{D}=10 \mu \mathrm{m}$

dromedary these structures are surrounded by glial cells in a phagocytic manner. So, pituicytes could play a phagocytic role, for example in the turnover of neurosecretory nerve fibers $[25,27]$ and catecholamine ones [28]. In addition, the high concen- tration of lysosomal acid phosphatase in rat pituicytes following water deprivation and lactation $[29,30]$ supports their strong phagocytic capacity [22]. And as described in rats [31], microglia may participate in this process. 

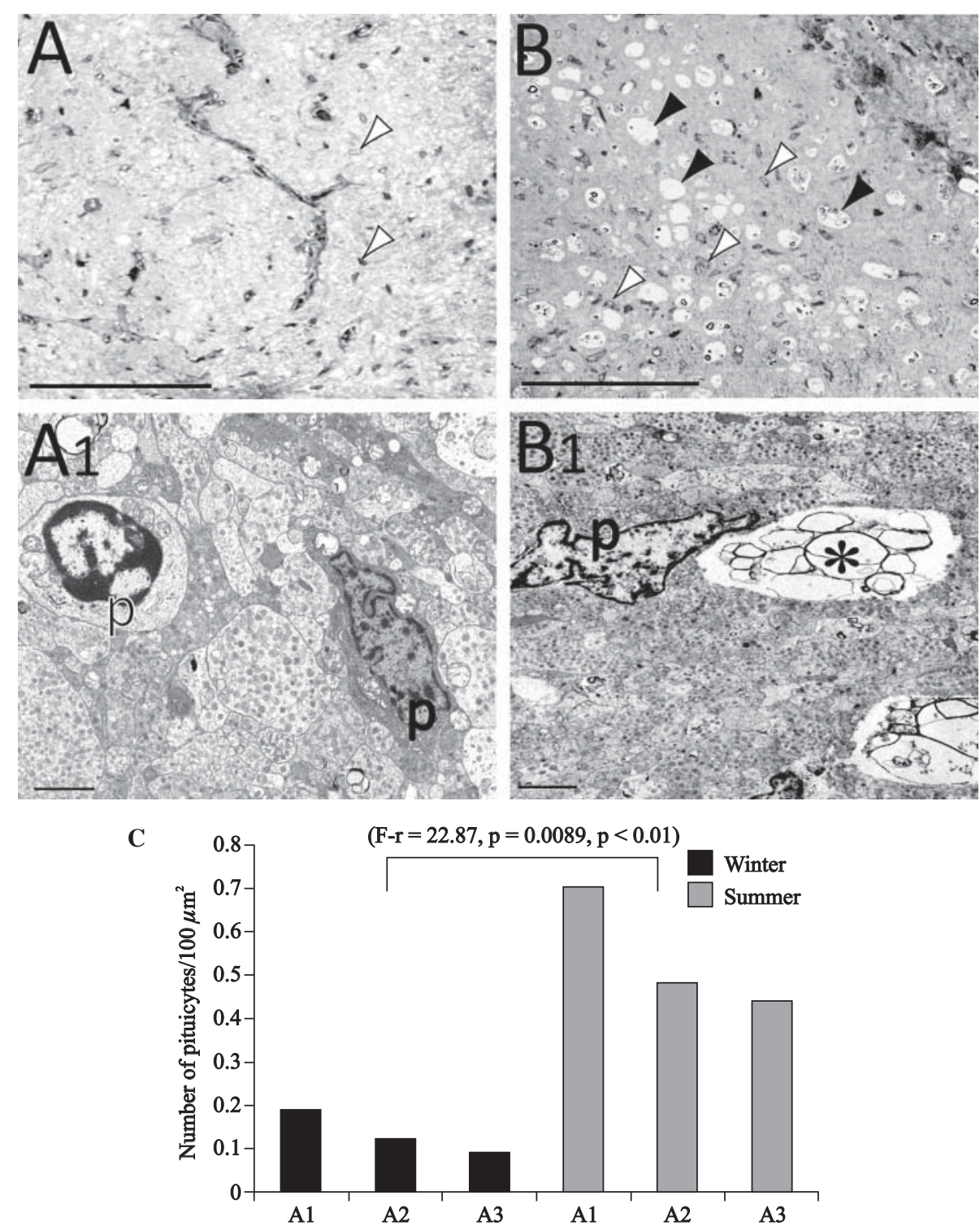

Figure 3. Dromedary neural lobe sections from winter (A, A1) and summer (B, B1) animals. (A, B) Pituicytes (white arrowheads) are more abundant and clustered in the summer than in the winter group, (B) Amorphous large structure (dark arrow heads). (A1) Pituicyte (p), (B1) enlarged amorphous large structure (asterisk), pituicyte (p).

Scale bar A, $\mathbf{B}=50 \mu \mathrm{m}(\mathbf{A}=\mathbf{B} \times 200) ; \mathbf{A 1}, \mathbf{B 1}=2 \mu \mathrm{m}$. (C) Analysis of number of pituicytes in winter and summer adult dromedary neural lobe (NL)

Several authors $[32,33]$ have proposed a macromolecular transportation between nerve endings and pituicytes, named ultraphagocytosis. Using horseradish peroxidase marker, Theodosis [34] demonstrated an active endocytic uptake of extracellular material by pituicytes, and the sequestration of the reaction product in the lysosomal bodies. The pituicytes would then provide a cytoplasmic machinery to catabolize the neurosecretory material transported via ultraphagocytosis or endocytosis. Therefore, the large light body in the phagocytic glial cell could be the ultra- structural evidence of such a function in the dromedary pars nervosa.

On the other hand, the NSG arrive at the nerve fiber endings early and, if not released, accumulate in the nerve fiber swellings [35]. An acute stimulation leads to granule depletion in nerve fiber endings and, if prolonged, depletion occurs also in the nerve fiber swellings [14]. So, these light bodies observed in the SG might be depleted nerve fiber swellings caused by a chronic stimulation with a large mobilization and progressive depletion of NSG to neurosecretory sites. 

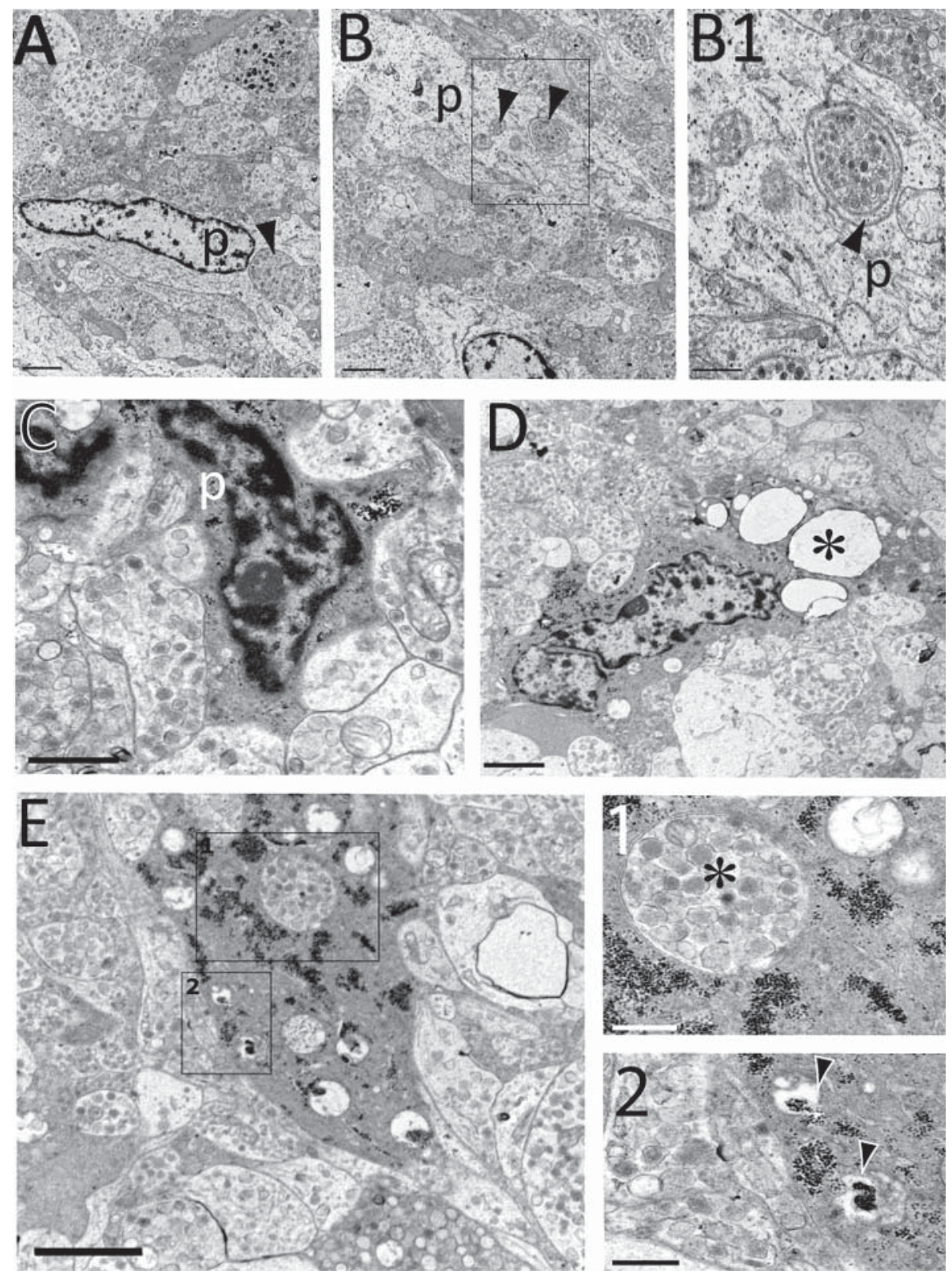

Figure 4. Electronograms of neural lobe pituicytes of winter animals. (A, B) Neurosecretory profiles (arrowheads) in the cytoplasm of light pituicyte (p). (B1) Enlarged rectangle from (B), extracellular space (arrowhead) between pituicyte (p) surrounding neurosecretory profile. (C) Dark pituicytes (p). (D) Dark pituicyte with light vacuoles (asterisk). (E) Neurosecretory axonal profiles with granulations (asterisk) (1), clear vacuoles with granules (arrowheads) (2). Scale bar A, B, C, D, E $=2 \mu \mathrm{m} ; \mathbf{B 1}=1 \mu \mathrm{m} ; \mathbf{E} 1, \mathbf{E} 2=0.5 \mu \mathrm{m}$

Parallel to the summer presence of large light bodies, an increase in the number of glial cells was also observed near them in the NL, probably to remove neurosecretory material or modulate neurosecretion. In fact, pituicytes are considered astrocyte-like glial cells $[36,37]$, and represent $23-30 \%$ of NL volume [38, 39]. The increased number of glial cells may be due to a large amount of neuronal debris or an increased neurohormonal demand. Earlier studies in the rat reported a mitotic NL activity [40] after stimulations inducing a neurohormonal demand, like a two week $\mathrm{NaCl}$ imbibition [41, 42] or dehydration [43]. Virard et al. [44] suggested that the rat NL contains glial progenitors. The pituicyte is also considered an osmotic sensor involved in the neurohypophysis hormone output [45]. The heterogeneity of dromedary NL glial cells, with four different types: light and dark in winter and phagocytic and granular in summer, suggests a relationship between the light type and the protoplasmic pituicyte, and the phagocytic type and a mi- 

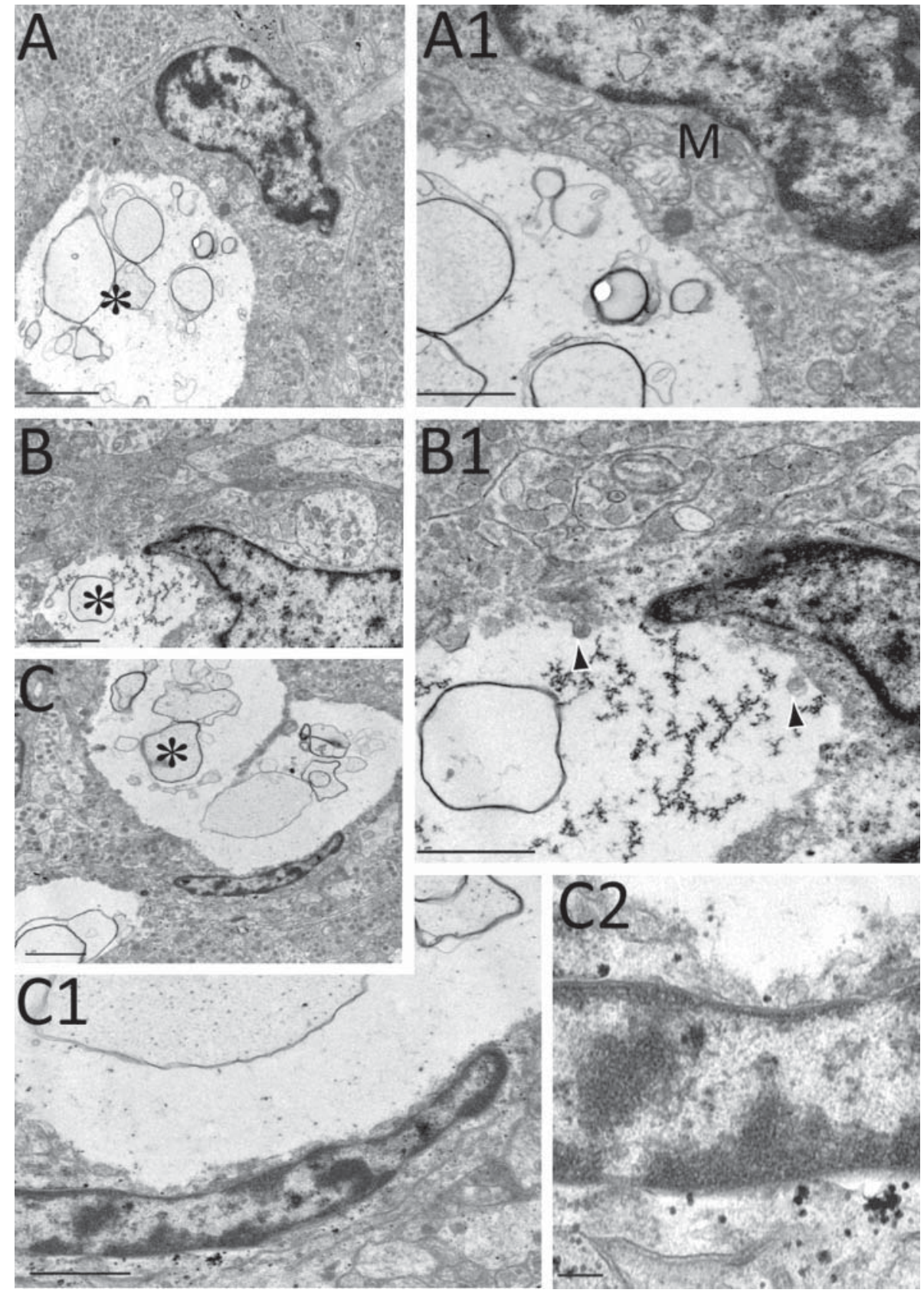

Figure 5. Electronograms of glial cells in early stages of phagocytosis, in neural lobe of summer animals group. (A, B, C) Degenerative light neurosecretory profiles (asterisks), irregular (A), concave (B) or elongated (C) nuclei of glial cells. (A1) Numerous mitochondria (M) in pituicytes. (B1) Neurosecretory degenerating profile with small granules (arrowheads). (C1 and C2), Swollen degenerating nerve fibers adjacent to the elongated glial cell nucleus. Scale bar A, B, C, C1 = $2 \mu \mathrm{m}$; A1, B1 $=1 \mu \mathrm{m} ; \mathbf{C} 2=0.2 \mu \mathrm{m}$

crogliocyte or a subpopulation of pituicytes. This data confirms and extends earlier observations showing that the morphology of pituicytes is notably functiondependent and varies in the same animal and between species. For example, associated with different functional stages, rat NL pituicytes present three morphological features [41], and human ones five types [26].
In the dromedary, the number of pituicyte processes is significantly different between summer and winter, but not the number of nerve fiber terminals contacting the BL. Therefore, in winter, associated with a reduced hormonal demand, the pituicytes increase their processes number on the BL to enclose nerve fiber terminals. The coverage of BL by neurosecreto- 

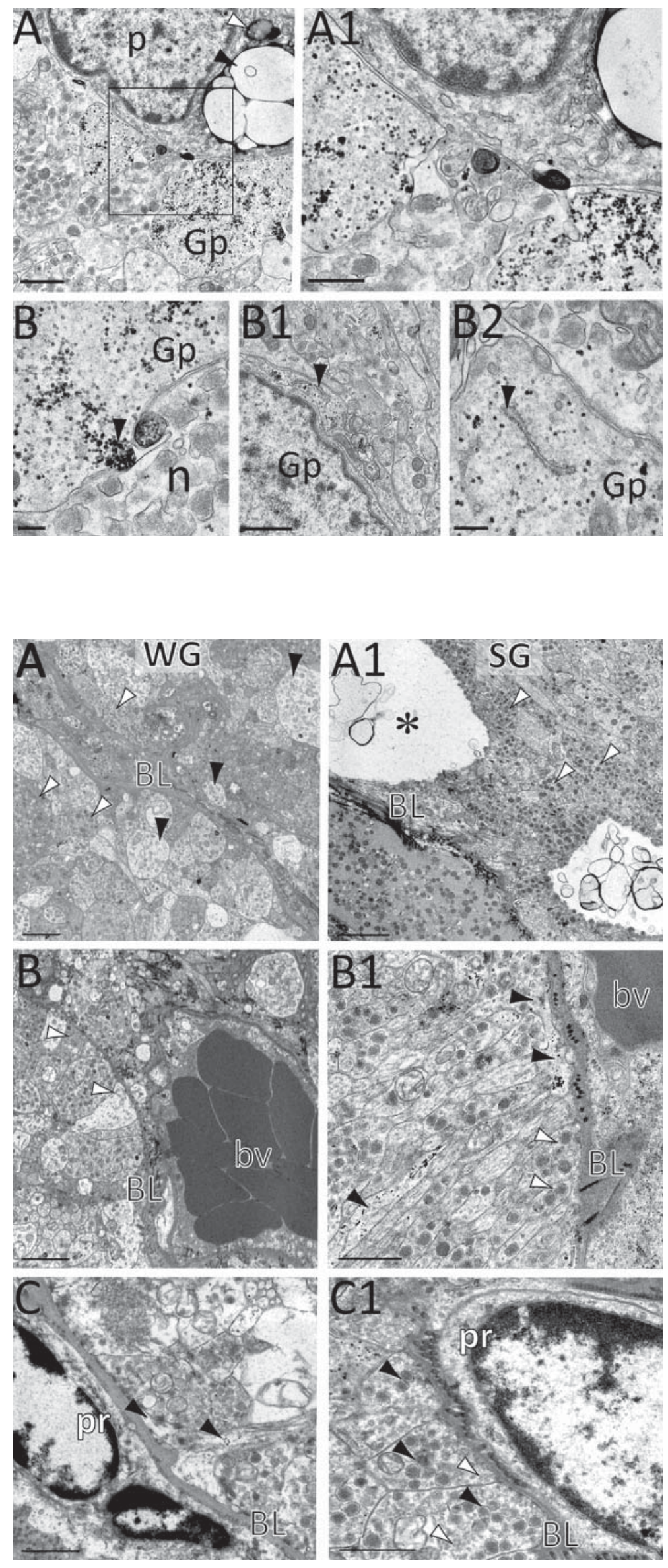

Figure 6. Electronograms of pituicyte in late stages of neural lobe phagocytosis and granular pituicyte type in summer group animals. (A) In pituicyte (p) cytoplasm a dark body (white arrowhead) is present near a phagosome (dark arrowhead), and processes of granular pituicyte type are adjacent (Gp). (A1) Enlarged rectangle from (A). (B) Dark granulations in neurosecretory ending (n) near the granular pituicyte (Gp). (B1, B2) Cisterns of the rough endoplasmic reticulum are shown (arrowheads) in the Gp cytoplasm and processes. Scale bar $\mathbf{A}=2 \mu \mathrm{m}$; $\mathbf{A 1}=0.5 \mu \mathrm{m} ; \mathbf{A 2}=1 \mu \mathrm{m} ; \mathbf{B}, \mathbf{B} 2=0.2 \mu \mathrm{m}$; $\mathbf{B} 1=1 \mu \mathrm{m}$

Figure 7. Electronograms of neurosecretory profiles at interlobular (A, A1) and neurovascular contact zone (B-C1) from winter (WG) (A-C) and summer (SG) (A1-C1) groups. (A) Dark (white arrowheads) and light (dark arrowheads) profiles of nerve fibers with a few dense granules, basal lamina (BL). (A1) Numerous dense granules in nerve fiber terminals (arrowheads), large empty light bodies (asterisk), basal lamina (BL). (B, B1) Neurovascular contact zone of the blood vessel (bv), endings of nerve fibers in (WG) and (SG) aligning in a palisade manner but differing in shape (white arrowheads), basal lamina (BL). (B1) Few pituicyte processes (dark arrowheads). (C) Pericyte (pr), a few pituicyte processes (arrowheads), basal lamina (BL).

(C1) Pericyte (pr), dense granules (dark arrowheads) and abundant microvesicles in nerve endings (white arrowheads), basal lamina (BL). Scale bar A, A1, $\mathbf{B}=2 \mu \mathrm{m}$; B1, C, $\mathbf{C 1}=1 \mu \mathrm{m}$ 
Table 1. Comparison of winter and summer neuronal and glial neurovascular contacts (means \pm SE and one-way ANOVA)

\begin{tabular}{|l|c|c|c|c|}
\hline Groups & $\begin{array}{c}\text { Number of nerve } \\
\text { terminals per } \mathbf{1 0 0} \boldsymbol{\mu} \mathbf{m ~} \mathbf{~ B L}\end{array}$ & $\begin{array}{c}\text { Number of pituicytes } \\
\text { processes per } \mathbf{1 0 0} \boldsymbol{\mu} \mathbf{m} \mathbf{~ B L}\end{array}$ & $\begin{array}{c}\text { Comparison of number } \\
\text { of nerve terminals }\end{array}$ & $\begin{array}{c}\text { Comparison of number } \\
\text { of pituicytes processes }\end{array}$ \\
\hline Winter & $56.33 \pm 2.68$ & $28 \pm 0.71$ & \multirow{2}{*}{$\mathrm{F}=2.15 ; \mathrm{p}=0.216$} & \multirow{2}{*}{$\mathrm{F}=9.37 ; \mathrm{p}=0.037$} \\
\hline Summer & $45 \pm 2.69$ & $14.50 \pm 0.81$ & \\
\hline
\end{tabular}

ry nerve fiber endings is a plastic phenomenon $[37$, 46], and pituicyte processes retract from both areas when hormone demand is high, allowing the neuronal terminals direct access to the perivascular space. Previous studies with neurohypophysis explants have shown that osmotic challenges produce similar modifications [47].

It should be mentioned that, in summer, the dromedary drinks more frequently than in winter, but, after walking very long distances under very high temperatures, it becomes dehydrated and its body temperature increases from $34^{\circ} \mathrm{C}$ to $42^{\circ} \mathrm{C}$, a situation causing failure in other higher mammals. The dromedary's adaptation avoids renal water loss [48, 49], probably related to an increased release of antidiuretic hormone due to the direct reduction of vascular contacts of pituicyte processes caused by the high temperature. If true, the dromedary's hypothalamo-neurohypophyseal system would be much more active in summer, and permanently prepared to avoid water deprivation. However, once well hydrated, the large amount of previously synthesized and stored material would enter into an autophagic process by specific glial cells, probably a subtype of pituicytes or microgliocytes.

\section{Acknowledgements}

This work was supported by SAF2008-01902 and 2009SGR1380. The technical assistance of J. Ortega and N. Cortadelas, Univ. of Barcelona, is gratefully acknowledged.

\section{References}

1. Jones CW, Pickering BT. Comparison of the effects of water deprivation and sodium chloride imbibition on the hormone content of the neurohypophysis of the rat. J Physiol (Lond). 1969;203:449-458.

2. Bargmann W, Knoop A. Elektronen mikroskopische Beobachtungen an der neurohypophyse. Z Zellforsch. 1957;46:242-251.

3. Green JD, Van Breemen VL. Electron microscopy on the pituitary and observations on neurosecretion. Am J Anat. 1955;97:177-228.

4. Green JD, Maxwell DS. Comparative anatomy of the hypophysis and observations on the mechanism of neurosecretion. In: Comparative endocrinology (ed. Goreman A), New York: J. Wiley; 1959:368-392.
5. Fujita H, Hartmann JF. Electron microscopy of neurohypophysis in normal, adrenaline-treated and pilocarpine-treated rabbits. Z Zellforsch. 1961;54:734-736.

6. Barer R, Lederis K. Ultrastructure of the rabbit neurohypophysis with special reference to the release of hormone. Z Zellforsch. 1966;75:201-239.

7. Tweedle CD. Ultrastructural manifestations of increased hormone release in the neurohypophysis. Prog Brain Res. 1983;60:259-272.

8. Nordmann JJ, Chevallier J. The role of microvesicules in buffering [Ca]i in the neurohypophysis. Nature. 1980;287:54-56.

9. Shaw FD, Morris JF. Ca localisation in the rat neurohypophysis. Nature. 1980;287:56-58.

10. Nordmann JJ, Cazalis M. Characterization of newly Formed and aged Granules in the neurohypophysis. J Neurochem. 1986;47:1534-1543.

11. Morris JF, Nordmann JJ, Dyball REJ. Structure-function correlation in mammalian neurosecretion. Int Rev Exp. Pathol. 1978;18:1-95.

12. Tweedle CD, Hatton GI. Morphological adaptability at neurosecretory axonal endings on the neurovascular contact zone of the rat neurohypophysis. Neuroscience. 1987;20:241-246.

13. Gajkowska B. Effect of high environmental temperature on the ultrastructure of the hypothalamo-neurohypophyseal system in rats. Neuropatol Pol. 1980;18:1-13.

14. Nordmann JJ. Hormone content and movement of neurosecretory granules in the rat neural lobe during and after dehydration. Neuroendocrinology. 1985;40:25-32.

15. Miyata S, Takamatsu H, Maekawa S et al. Plasticity of neurohypophysial terminals with increased hormonal release during dehydration: Ultrastructure and biochimical analyses. J Comp Neurol. 2001;434:413-427.

16. Boeck P. Romeis Mikroskopische Technik, 17th ed. Urban \& Schwarzenberg, Munich/Vienna/Baltimore; 1989:502-503.

17. Reynolds ES. The use of lead citrate at high $\mathrm{pH}$ as an electron-opaque stain in electron microscopy. J Cell Biol. 1963;17:208-212.

18. Kawamoto K, Kawashima S. Ultrastructural changes and proliferation of pituicytes in mouse posterior lobe during water deprivation and rehydration. Acta Anat (Basel). 1984;119:136-141.

19. Hatton GI. Function-related plasticity in hypothalamus. Annu Rev Neurosci. 1997;20:375-397.

20. Picard D, Boudier JA, Tasso F. Intracellular regulatory mechanisms of neurosecretory activity. In: Scott E, Kozlowski G, Weindl A, ed. Brain- Endocrine Interaction III. Neural Hormones and Reproduction, Karger: Basel; 1974:33-45.

21. Rufener C. Autophology of secretory granules in rat neurohypophysis. Neuroendocrinology. 1973;13:314-320.

22. Dellman HD, Stoeckel ME, Porte A, Stutinsky F. Ultrastructure of the neurohypophysial glial cells following stalk transection in the rat. Experiencia. 1974;30:1220-1222.

23. Sterba, G, Bruckner G. Zur Funktion der ependymalen Glia in der Neurohypophyse. Z Zellforsch. 1967;81:457-473. 
24. Dellmann HD, Owsley PA. Investigations on the hypothalamoneurohypophyseal neurosecretory system of the grass frog (Rana pipiens) after transection of the proximal neurohypophysis. II. Light and electron microscopic findings in the disconnected distal neurohypophysis with special emphasis on the pituicytes. Z Zellforsch. 1969;94:325-336.

25. Dellmann DH, Rodriguez EM. Herring bodies: an electron microscopic study of local degeneration and regerenation of nerosecretory axons. Z Zellforsch. 1970;111:293-315.

26. Takei Y, Seyama S, Pearl GS, Tindall GT. Ultrastructural Study of the Human Neurohypophysis II. Cellular Elements of Neural Parenchyma, the Pituicytes. Cell Tissue Res. 1980;205:273-287.

27. Tweedle CD, Hatton GI. Evidence for dynamic interactions between pituicytes and neurosecretory axons in the rat. Neuroscience. 1980a;5:661-671.

28. Baumgarten HG, Björklund A, Holstein AF, Nobin A. Organization and ultrastructural identification of the catecholamine nerve terminals in the neural lobe and pars intermedia of the rat pituitary. $Z$ Zellforsch. 1972;126:483-517.

29. Boer GJ, Jongkind JF. Quantitative lysosomal enzyme activity changes in the neural lobe of the rat following water deprivation and lactation. J Neurochem. 1974;22:965-970.

30. Boer GJ, Van Rheenen-Verberg C. Acid phosphatase in rat neurohypophyseal dispersions and its fractions enriched for neurosecretosomes and pituicytes after water deprivation and lactation. Brain Res. 1976;114:279-292.

31. Pow DV, Perry VH, Morris JF, Gordon S. Microglia in the neurohypophysis associate with and endocytose terminal portions of neurosecretory neurons. Neuroscience. 1989;33:567-578.

32. Kurosumi K, Matsuzawa T, Kobayashi Y. On relation between the release of neurosecretory substance and lipid granules of pitulcytes in the rat neurohypophysis. Gunma Symposia on Endocrinology. 1964;87-118.

33. Krsulovic J, Bruckner G. Morphological characteristics of pituicytes in different functional stages. Z Zellforsch. 1969;99:210-220.

34. Theodosis DT. Endocytosis in glial cells (pituicytes) of the rat neurohypophysis demonstrated by incorporation of horseradish peroxidase. Neuroscience. 1979;4:417-525.

35. Heap PF, Jones CW, Morris JF, Peckering BT. Movement of neurosecretory product through the anatomical comparte- ments of the rat neural lobe of the pituitary gland. Cell Tissue Res. 1975;156:483-497.

36. Suess U, Pliska V. Identification of the pituicytes as astroglial cells by indirect immunofiuorescence-staining for the glial fibrillary acidic protein. Brain Res. 1981;221:27-33.

37. Hatton GI. Pituicytes, glia and control of terminal secretion. J Exp Biol. 1988;139:67-79.

38. Reinhardt HF, Henning LC, Rohr HP. Morphometrische-ultrastruktuelle untersuchungen am nucleus supraopticus der Ratte nach dehydration. Z Zellforsch. 1969;102:172-181.

39. Nordmann JJ. Ultrastructural morphometry of the rat neurohypophysis. J Anat. 1977;123:213-218.

40. Leveque F, Smal M. The relationship of pituicytes to the posterior lobe hormones. Endocrinology. 1959;65:909-915.

41. Krsulovic J, Bruckner G. Morphological characteristics of pitulcytes in different functional stages. Z Zellforsch. 1969;99:210-220.

42. Paterson JA, Leblond CP. Increased proliferation of neuroglia and endothelial cells in the supraoptic nucleus and hypophysial neural lobe of young rats drinking hypertonic sodium chloride solution. J Comp Neurol. 1977;175:373-390.

43. Murugaiyan P, Salm AK. Dehydration-induced proliferation of identified pituicytes in fully adult rats. Glia. 1995;15: $65-76$.

44. Virard I, Gubkina O, Alfonsi F, Durbec P. Characterization of heterogeneous glial cell populations involved in dehydration-induced proliferation in the adult rat neurohypophysis. Neuroscience. 2008;151:82-91.

45. Rosso L, Mienville JM. Pituicyte modulation of neurohormone output. Glia. 2009;57:235-243.

46. Carithers J, Dellman HD, Bealer SL, Brody MJ, Johnson AK. Ultrastructural aspects of anterolateral third ventricule lesions on supraoptic nuclei and neural lobes of rats. Brain Res. 1981;220:13-29.

47. Perlmutter LS, Hatton GI, Tweedle CD. Plasticity in the in vitro neurohypophysis: effects of osmotic changes on pituicytes. Neuroscience. 1984;12:503-511.

48. Schmidt-Nielsen B, Schmidt-Nielsen K, Houpt TR, Jarnium SA. Body temperature of the camel ant its relation to water economy. Am J Physiol. 1957;188:103-112.

49. Schmidt-Nielsen K. Desert animals: physiological problems of heat and water. Oxford: clarendon press; 1964.

Submitted: 2 October, 2011

Accepted after reviews: 10 January, 2012 